\title{
Para além do plenário: o papel decisório das comissões no Senado Federal brasileiro
}

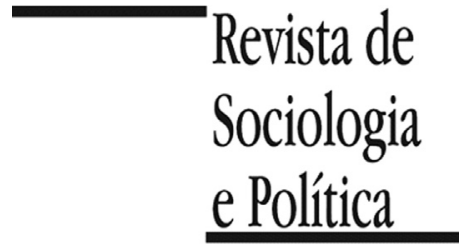

DOI 10.1590/1678-987320287505

\author{
Bruno de Castro Rubiatti' \\ IInstituto de Filosofia e Ciências Humanas, Programa de Pós-Graduação em Ciência Política, Universidade Federal do Pará, \\ Belém, PA, Brasil.
}

PALAVRAS-CHAVE: Legislativo; Senado; Sistema de Comissões; Processo decisório; Estudos Legislativos

RESUMO Introdução: A área de estudos Legislativos no Brasil é forte em pesquisas sobre a Câmara dos Deputados, relegando o Senado Federal a segundo plano. Apesar de crescente número de pesquisas sobre a câmara alta brasileira, há ainda temas pouco trabalhados, em especial o seu processo legislativo. Este artigo analisa o papel decisório das Comissões no Senado federal brasileiro. Materiais e Métodos: Analisamos os resultados dos projetos de lei que tramitaram no Senado entre 1999 e 2018, totalizando 6.493 proposições entre Projetos de Lei Ordinária, Projetos de Lei Complementar e Emendas Constitucionais. Destacamos as seguintes variáveis: resultado, propositor, local de decisão (plenário ou comissões) e área temática. A partir desses dados é possível perceber não só o papel decisório do sistema de comissões, mas também as transformações ocorridas no próprio Senado nesse período. Resultados: As comissões são responsáveis por quase metade das decisões tomadas no Senado Federal. Nota-se um crescimento das decisões finais pelas comissões entre 2007 e 2014. Essas legislaturas são marcadas por coalizões de governo amplas e heterogêneas, o que reforça o argumento de que coalizões desse tipo dificultam a delegação e a concentração de poderes nos líderes partidários. As decisões tomadas no âmbito das comissões se concentram em projetos originados no próprio Senado. Projetos propostos pelo Executivo só foram examinados terminativamente nas comissões nas legislaturas anteriores a esse período. Discussão: As comissões desempenham papel relevante no Senado brasileiro. Além de serem espaços informacionais e de estabelecimento de acordos políticos, elas também são instâncias decisórias. A utilização das prerrogativas das comissões para alteração de projetos está relacionada com a capacidade de centralização do processo decisório nas lideranças partidárias. Em contextos onde a coalizão política majoritária é mais heterogênea, e a centralização se torna mais difícil, a utilização das comissões como espaço decisório aumenta.

Recebido em 18 de Junho de 2019. Aprovado em 9 de Junho de 2020. Aceito em 29 de Setembro de 2020.

\section{Introdução}

$\mathrm{D}$ esde a redemocratização os Estudos Legislativos brasileiros vêm ganhando força, aumentando seu volume e sua agenda de pesquisa. Todavia, alguns temas ainda permanecem pouco estudados. Dentre esses temas se destacam o papel do Senado e o sistema de comissões. O bicameralismo brasileiro apresenta alta simetria entre os poderes legislativos das câmaras e incongruência (possui diferentes forma de seleção dos membros para cada casa). Por esse motivo, ele é classificado como forte (Llanos \& Nolte, 2003). Porém, o tratamento dado ao Senado nos Estudos Legislativos brasileiros não condiz com a própria formatação do sistema bicameral do país.

De forma semelhante, os sistemas de comissões em ambas as casas legislativas do Brasil também são colocados em segundo plano nas análises sobre o Legislativo. Porém, estudos recentes mostram que as comissões exercem um papel chave na análise das propostas legislativas (Freitas, 2016) e que a tomada de decisão final nas comissões tem crescido no decorrer das primeiras décadas do século XXI (Almeida, 2019). Entretanto, essa bibliografia foca nas comissões da Câmara dos Deputados. Por esse motivo, o presente artigo visa contribuir com os Estudos legislativos brasileiros a partir de uma análise do papel 
decisório das comissões no Senado, destacando a capacidade de decisão das comissões nessa casa legislativa.

Cabe notar que nas últimas décadas aumenta o número de pesquisas que abordam papel do Senado brasileiro no processo decisório. Trabalhos que abordam em perspectiva comparada a força do bicameralismo (Llanos \& Nolte, 2003) e os poderes do Senado (Neiva, 2008), ou estudos focados no caso específico do Brasil, destacando: 1) variáveis socioeconômicas com idade (Llanos \& Sanchéz, 2008; Neiva, 2010), gênero (Neiva, 2008; Bohn, 2008), diferenças regionais (Backes, 2008) e escolaridade (Neiva \& Izumi, 2012); 2) o papel do Senado no processo decisório brasileiros, focando na produção legislativa do Senado (Araújo, 2008), comparando a abrangência das proposições de senadores e deputados federais (Ricci, 2008), as funções de controle da câmara alta (Lemos \& Llanos, 2008), o papel revisor da câmara alta (Rubiatti, 2017a); 3) a composição e comportamento dos parlamentares na Segunda Câmara, observando as diferenças na composição partidária das duas casas legislativas (Rubiatti, 2015), os padrões de comportamento dos Senadores (Neiva, 2011a, 2011b; Neiva \& Soares, 2013; Melo \& Batista, 2012; Izumi, 2016), a carreira política no Senado (Lemos \& Ranincheski, 2008), a organização interna da câmara alta (Rubiatti, 2017b). Desta forma, é possível notar um acúmulo de trabalhos sobre o Senado que permite observar o seu funcionamento e seu papel no processo decisório brasileiro. Porém esses estudos ainda formam uma minoria dentre os trabalhos que se debruçam sobre o Legislativo brasileiro.

Da mesma forma, também é possível pontuar a existência de trabalhos que tratam do sistema de comissões no Brasil. Essa bibliografia se debruça sobre 1) determinantes de seleção dos membros para as diferentes comissões (Santos, 2002; Muller, 2005; Araújo 2017), a ocupação dos cargos de titulares nas comissões (Lemos \& Ranincheski, 2008; Pereira, 2019; Souza e Silva, 2019; Ferreira, 2019); 2) o uso do poder conclusivo/terminativo e a produção de pareceres e decisões nas comissões (Lemos, 2008; Amaral, 2011; Ricci \& Lemos, 2004) e a questão da representação feminina nas comissões (Busanello \& Rehbein, 2017; Perlin, 2019); 3) o papel informacional das comissões (Santos \& Almeida, 2011; Santos \& Canello, 2016) e a função das comissões no presidencialismo de coalizão brasileiro (Pereira \& Mueller, 2000); 4) o sistema de comissões em perspectiva comparada (Rocha \& Barbosa, 2008) e 5) caracterização normativa-institucional e transformações no sistema de comissões (Almeida, 2015; Almeida, 2019; Vasquez \& Freitas, 2019). Porém, aqui também o foco se concentra no sistema de comissões da Câmara dos Deputados e em comissões específicas do Senado. Isto posto, esse artigo busca contribuir com os Estudos Legislativos a partir do estudo das decisões tomadas no Senado, partindo das perguntas: Qual é a participação das comissões nas decisões tomadas na câmara alta? Em que temas as comissões tomam decisões? Há variações entre legislaturas e governos na atuação das comissões?

Assim, este trabalho tem por objetivo analisar a capacidade de decisão das comissões do Senado dentro do processo legislativo, a partir das decisões tomadas no interior da câmara alta brasileira. Para tanto, foram levantados os dados referentes as decisões do Senado entre os anos de 1999 até 2018, agrupando essas decisões a partir de a) local da decisão (comissões ou plenário), b) resultado, c) órgão propositor e d) área temática. A análise também se desenvolverá por Legislatura, o que permite notar as transformações ocorridas no processo decisório desta casa legislativa.

Para atingir seu objetivo, o artigo está dividido em três partes, além dessa Introdução (I) e das Considerações Finais (V). Na segunda parte se fará uma caracterização do Senado brasileiro e dos estudos sobre sistema de comissões no Brasil. Na terceira parte é analisada a atuação das comissões e do plenário 
nas decisões tomadas no Senado, focando a participação das comissões e a variação ocorrida entre as legislaturas e diferentes governos. Na quarta parte se analisa o poder positivo das comissões, isto é, quais as matérias aprovadas pelas comissões do Senado a partir dos órgãos propositores e área temática dos projetos. A partir desses dados é possível apontar o papel decisório do sistema de comissões do Senado, mostrando que as comissões não se limitam a decidir sobre agendas simbólica ou honorifica e, principalmente, que elas apresentam importante participação nas decisões finais tomadas nessa casa, sendo que essa participação cresce em conjunturas onde a coalizão governista se mostra heterogênea.

\section{O Senado e as comissões no processo legislativo brasileiro}

Quando se trata de sistemas bicamerais, duas dimensões formuladas por Lijphart (2008) são utilizadas para definir sua força: Simetria e Incongruência. Grosso modo, a primeira se refere aos poderes dados as casas legislativas para participar do processo decisório, enquanto que a incongruência se relaciona com a forma de seleção dos membros de cada Câmara. Tendo essas duas dimensões como referência Llanos e Nolte (2003) buscam analisar os sistemas bicamerais nas Américas. Para tanto, os autores (Llanos e Nolte, 2003) formulam nove dispositivos institucionais que reforçam a incongruência e seis dispositivos para a simetria e a partir deles classificam o sistema brasileiro como forte, pois conjuga forte simetria e alto grau de incongruência na seleção dos membros de cada uma das casas.

Além dessa classificação de força do sistema bicameral, Neiva (2008) destaca que o Senado brasileiro possui amplas prerrogativas, o que lhe colocaria entre os mais fortes entre os 51 países analisados. Para classificar os Senados desses países, o autor (Neiva, 2008) elabora um índice formado por vinte e sete indicadores, divididos em quatro grupos: 1) indicadores relacionados com a função de legislar, 2) controlar autoridades, 3) nomeações e 4) outras atribuições menores. A partir desse índice o Senado brasileiro atinge 31 pontos, ficando atrás apenas da Bolívia.

Mesmo que a justificativa formal para a existência do Senado brasileiro seja a representação igualitária dos estados, estudos sobre a produção legislativa dessa casa indicam que a atuação dos Senadores não obedece uma lógica estritamente territorial. Neiva e Soares (2013) apontam que as variáveis referentes à partidos e coalizão de partidos governantes mostram-se mais relevante para explicar o comportamento dos Senadores em plenário e que a influência dos governadores não se mostra expressiva, isso tanto para as matérias legislativas gerais, quanto para as de cunho federativo. Melo e Batista (2012) pontuam que as diferenças na organização interna das duas casas legislativas, em especial as diferenças encontradas nos poderes dos líderes partidários de cada uma, têm impacto sobre o comportamento dos parlamentares: há maior índice de disciplina na Câmara dos Deputados do que no Senado. Contudo, cabe notar que, mesmo com um índice de disciplina relativamente mais baixo, ainda se observa um padrão de comportamento disciplinado no Senado brasileiro.

Esse caráter não-territorial na atuação do Senado também pode ser visto na produção legislativa dessa casa. Araújo (2008) aponta que as iniciativas presentes no Senado são predominantemente nacionais, e não paroquiais. No mesmo sentido, Ricci (2008), ao analisar as iniciativas legislativas da Câmara dos Deputados e do Senado aponta que as políticas locais ocupam espaço minoritário em ambas as casas. Desta forma, a imagem dos senadores como tendo uma atuação voltada primordialmente para seus estados de origem não se sustentaria com os dados sobre comportamento parlamentar e sobre as iniciativas legislativas. 
Vale destacar que o Senado tem, além de suas funções de iniciar projetos de lei, a função de câmara revisora. Esse ponto se destaca pois todo projeto iniciado por Deputados Federais, Executivo e outros agentes que possuem a prerrogativa de iniciativa, começam seu trâmite pela Câmara dos Deputados, colocando o Senado como câmara revisora. Rubiatti (2017a) aponta que o Senado apresenta significativa capacidade de retenção de projetos. Em outras palavras, ao realizar a função de câmara revisora, o Senado utilizada de forma consistente a retenção de projetos, finalizando o processo na própria casa a partir de rejeição, arquivamento regimental e declarando o projeto prejudicado. Em suma, ao exercer a função de câmara revisora, o Senado não se mostra como mero "carimbador" das decisões da primeira câmara, exercendo poder de veto a muitas medidas aprovadas pelos deputados.

Além da questão desse poder de veto, cabe destacar que o Senado também propõe alterações (emendas e substitutivos) aos projetos aprovados pela Câmara dos Deputados e em revisão no Senado, além de aprovar os projetos. Caso haja emendas ou substitutivos, o projeto retorna para análise da Câmara dos Deputados, que terá que decidir se aceita ou não as alterações feitas pelo Senado. Em caso de aprovação, o projeto em revisão no Senado segue para sanção presidencial. Dessa forma, mesmo retendo parte considerável dos projetos em revisão, o Senado não pode ser considerado uma casa obstrucionista, uma vez que mais da metade desses projetos seguem o trâmite bicameral (Rubiatti, 2017a).

Esse tratamento dos projetos em revisão no Senado, varia de acordo com o propositor, sendo os projetos do Executivo aprovados com maior frequência e maior rapidez, enquanto que os projetos apresentados por deputados tendem a demorar mais e a serem retidos com maior frequência no processo de revisão na câmara alta (Rubiatti, 2017a; 2018).

Somado a isso, o Senado também tem forte papel propositivo. Como mostra Araújo (2008), entre 1989 e 2000, 72,2\% dos projetos apreciados na câmara alta tinham como origem o próprio Senado. Todavia, os projetos dos próprios senadores também são os que sofrem maior retenção na casa. Assim, o Senado exerce um importante papel tanto filtrando os projetos de autoria dos seus próprios membros, quanto exercendo a função de câmara revisora. Somado esse papel a simetria e incongruência do bicameralismo brasileiro e as diferenças na organização das duas casas legislativas do país, faz-se necessário o estudo da câmara alta para uma melhor compreensão do processo decisório brasileiro.

Um dos elementos na organização interna das casas legislativas é o sistema de comissões. Ao tratar do estudo desse sistema, três modelos de comportamento legislativos formulados para a análise do Congresso dos EUA são centrais, uma vez que, com adaptações, norteiam as pesquisas sobre o parlamento brasileiro: os modelos distributivo, informacional e partidário.

O modelo distributivista se caracteriza pela lógica da conexão eleitoral: partindo da perspectiva de que os parlamentares individuais buscam a reeleição e, ao perceberem a pouca capacidade que possuem para influenciar as grandes tendências nacionais, a estratégia para atingir esse objetivo se vincula a busca de benefícios para seus distritos eleitorais (Mayhew, 2004). Assim, a questão básica do modelo distributivista é "quem ganha o que, e à custa de quem?", isto é, trata da decisão sobre a alocação de recursos para os distritos eleitorais dos congressistas, e como distribuir os custos dessa alocação.

Sendo assim, os parlamentares individuais utilizariam seus recursos para potencializar seus votos nos respectivos distritos. Para isso, utilizariam as estratégias de i) advertising, ii) credit-claiming, iii) position taking, e iv) utilização da própria estrutura organizacional do Congresso (em especial, os 
gabinetes e as comissões) para otimizar a relação com seus eleitores. Portanto, a organização do Congresso seria feita de forma a possibilitar esses ganhos para os parlamentares.

Dentro dessa perspectiva, cada comissão seria responsável pelas políticas direcionadas para áreas temáticas específicas, sendo ocupadas por legisladores fortemente interessados nessa temática. Portanto, a posição da comissão será extremada, uma vez que em sua composição é predominante a presença de outliers, e homogênea, ficando distante da posição média do plenário. Essa forma de organização gera uma espécie de acordo tácito, onde nenhum parlamentar de outra comissão se colocaria contrário ao que foi decidido em outra comissão (Mayhew, 2004). Assim,

A teoria distributiva ou hipótese dos ganhos de troca (gains from exchange) sugere que o equilíbrio da organização legislativa está apoiado sobre a alocação da influência legislativa de acordo com a extremidade e intensidade das preferências dos legisladores. De acordo com esta tradição, adotando este princípio de organização, uma legislatura pode não só invalidar a imprevisibilidade da regra da maioria, mas também alocar recursos clientelistas para os distritos eleitorais preferenciais dos legisladores que aderem a este acordo tácito (Nascimento, 2010, p.367)

Já o modelo informacional coloca a questão da incerteza como central para a análise do Legislativo. Para Krehbiel (1991) os parlamentares têm que tomar decisões sobre múltiplas políticas complexas, o que exigiria conhecimento técnico e experiência, ou seja, expertise. Todavia, adquirir essa expertise gera custos. Por esse motivo, o Parlamento se organiza de forma a "gerar incentivos para a criação dessa expertise, isto é, a habilidade de gerar informações relevantes para diminuir a incerteza na tomada de decisão" (Rubiatti, 2019, p. 15). Além de gerar informação visando a diminuição da incerteza, Krehbiel (1991) aponta também a necessidade desse Legislativo induzir o compartilhamento dessa informação, o que possibilitaria ganhos para o conjunto dos parlamentares. Nesse modelo, as comissões exercem esse duplo papel de geração de expertise e incentivos para compartilhar as informações.

Dessa forma, o modelo informacional proposto por Krehbiel (1991) teriam como características: i) as comissões não seriam compostas por membros com preferências extremas, já que isso acarretaria ineficiência informacional, e as escolhas favoreceriam demasiadamente esses membros; ii) apenas de forma excepcional há possibilidade de membros com preferências extremas comporem as comissões; mas só se os custos de especialização desses membros forem menor que a perda informacional que acarretam; iii) a comissão será heterogênea em sua composição, garantindo maiores ganhos informacionais; iv) haverá regras restritivas, reforçando as comissões frente ao plenário, garantindo primazia para as primeiras, uma vez que, com isso, se gera maiores incentivos para a especialização.

Por fim, o modelo partidário aponta os partidos políticos como elementos centrais na direção do processo legislativo. Nessa perspectiva, o pertencimento ao partido traz vantagens ao parlamentar, especialmente no caso dos partidos majoritários. Isso porque o partido majoritário é capaz de controlar a agenda legislativa, gerando um bom número de aprovações de políticas, garantindo, dessa maneira uma boa reputação para o partido. Como a reputação do partido é um bem coletivo, a boa reputação gera efeitos positivos nas chances de eleição de todos os seus membros e na possibilidade de ampliação de seus membros (Cox \& McCubbins, 1993).

Para que o partido consiga gerar política e, consequentemente, boa reputação, é necessário que ele se comporte como um ator coletivo, isto é, que os parlamentares pertencentes ao partido priorizem um comportamento partidário 
a um comportamento individualista. Em outras palavras, é necessária a coordenação da ação no Legislativo. É nesse ponto que entra uma figura central no modelo partidário: a liderança.

Cabe ao líder partidário coordenar a ação dos membros de seu partido. Para tanto, o líder deve possuir recursos para premiar comportamentos desejados e punir os indesejáveis. Com isso, a disciplina será fortalecida e os possíveis desgastes à reputação do partido, gerados por parlamentares priorizando estratégias individuais, seriam mitigados. Por esse motivo, a posição do líder partidário deve ser diferenciada das dos demais parlamentares: o líder deve ter incentivos para utilizar esses recursos para induzir a disciplina dos parlamentares de seu partido (Cox \& McCubbins, 1993). Como o “o comportamento individualista acabaria por acarretar resultados sub-ótimos para todos os membros, essa forma de organização acaba por ser preferida pelos legisladores" (Rubiatti, 2019, p. 17)

No modelo partidário as comissões aparecem como espaços privilegiados para o controle da agenda, definindo as matérias que chegarão ao plenário. Dessa forma, a ocupação das comissões se daria de maneira a privilegiar os membros que apresentem maior lealdade aos interesses partidários. Somado a isso, a permanência de um parlamentar em determinada comissão estaria vinculada a sua capacidade de conseguir barrar ou aprovar os projetos, de acordo com os interesses do seu partido (Cox \& Mccubbins, 1993).

Cabe notar que esses modelos servem de fundamento para os estudos das comissões, porém, o sistema de comissões adotado no Brasil não se encaixa perfeita e exclusivamente em nenhum deles. Como apontado por Araújo (2017), o que caracterizaria o sistema brasileiro é um hibridismo institucional, que permitiria ganhos informacionais, de troca e partidários. Porém, mesmo com essa característica hibrida, o modelo partidário seria mais proeminente.

Atualmente, o sistema de comissões no Senado Brasileiro é formado por treze comissões temáticas mais a mesa diretora, chamada de Comissão Diretora (CDIR). O número de membros titulares nas comissões temáticas varia de 11 a 27. Regimentalmente, cabe às comissões, entre outras funções, discutir e votar projeto de lei, realizar audiências públicas, convocar Ministros de Estado ou quaisquer titulares de órgãos diretamente subordinados à Presidência da República, solicitar depoimento de qualquer autoridade ou cidadão, acompanhar, fiscalizar e controlar as políticas governamentais pertinentes às áreas de sua competência, exercer a fiscalização e controle dos atos do Poder Executivo, opinar sobre o mérito das proposições submetidas ao seu exame, emitindo o respectivo parecer.

Um ponto a se destacar ao tratar das comissões no Senado do Brasil é o Poder Terminativo. Esse poder se refere aos casos em que as comissões decidem sobre os projetos, sem a necessidade de eles passarem pelo plenário, ou seja, a comissão decide se o projeto será aprovado ou rejeitado sem ouvir o plenário. No Senado brasileiro, os projetos de lei ordinária iniciados pelos próprios senadores podem apreciados terminativamente pelas comissões, salvo quando há recurso de 1/10 de seus membros. Além deles, os projetos que foram objeto de decisão conclusiva das comissões da Câmara dos Deputados também podem ser assim decididos no Senado, por decisão do Presidente da casa, após ouvir os líderes partidários (art. 91, RISF).

Porém, mesmo quando não é possível apreciar terminativamente os projetos, ainda cabe as comissões estudá-los e emitir parecer sobre eles. Somado a esse poder, as comissões também podem propor projetos. Sobre isso, Lemos (2008) aponta que entre 1988 e 1994, as propostas das comissões do Senado brasileiro representavam somente $4 \%$ do total de propostas na área social, mas 
sua taxa de aprovação foi de $75 \%$, muito superior as dos projetos apresentados individualmente, que atingiram penas $6,49 \%$ de taxa de sucesso.

Assim como na Câmara dos Deputados, se busca a representação proporcional dos partidos políticos nas comissões do Senado. Porém, essa proporcionalidade não é perfeita por dois motivos: 1) o problema das frações ou sobras que resultam do cálculo para a distribuição de cadeiras nas comissões e 2) há uma regra de representação de minorias, ou seja, mesmo que não tenham tamanho para estar representados, todos os partidos têm pelo menos uma cadeira em uma comissão.

Em suma, pode-se notar que o sistema de comissões do Senado brasileiro é complexo e estruturado, "tendo importância crescente no processo legislativo brasileiro, tanto através da utilização do poder terminativo/conclusivo quanto por serem o local privilegiado da discussão para a formação dos relatórios, que serão votados em plenário" (Rubiatti, 2019, p. 25). Por fim, a maneira como são formadas as comissões, respeitando a proporcionalidade entre o tamanho das bancadas e de membros nelas, pode reforçar o papel dos partidos políticos no controle da atividade legislativa (Rubiatti, 2017b).

Nota-se um interesse crescente de pesquisa sobre o papel que as comissões desempenham dentro da estrutura de poder e no funcionamento do processo legislativo. Todavia, seguindo o mesmo padrão visto nos trabalhos sobre o Legislativo em geral, esses trabalhos focam na Câmara Baixa. O trabalho de Pereira e Mueller (2000) aponta que, mesmo o pedido de urgência enfraquecendo o papel das comissões, o Executivo buscaria formar maiorias também nas comissões de seu interesse e, juntamente com o papel informacional desempenhado pelas comissões, isso explicaria a existência de um complexo sistema de comissões na Câmara dos Deputados.

Freitas (2016, p.78) destaca que as comissões seriam, em geral, tratadas como fracas pela literatura dos Estudos Legislativos brasileiros, sendo que essa visão estaria alicerçada na "possibilidade de que, uma vez pedida urgência legislativa para um projeto, esse possa ser retirado das comissões sem deliberação das mesmas". Porém, analisando os Pedidos de Urgência, a autora constata que $22 \%$ dos Pedidos de Urgência são feitos após o projeto já ter passado pelas comissões, isto é, seguido o rito ordinário nas comissões. Dessa forma, esses Pedidos de Urgência não visam encurtar o debate legislativo, nem contornar as comissões, mas sim são um instrumento utilizado para colocar o projeto em pauta. Em suma, mesmo com a existência do dispositivo do Pedido de Urgência, as comissões continuariam a exercer importante papel na aprovação, emendamento ou rejeição de projetos dentro do Legislativo.

Além desse poder de decisão, as comissões também teriam importante papel no emendamento e apresentação de substitutivos aos projetos. Tendo isso em vista, Freitas (2016) destaca o papel dos Relatores nas comissões como os responsáveis por instruir o processo de discussão e debate dos projetos no interior das comissões. Em suma,

As comissões têm um papel institucional a desempenhar, qual seja, o de avaliar os projetos, deliberar sobre eles, convocar audiências públicas e reunir informação técnica para avaliá-los de forma embasada. O relator, escolhido pelo presidente da comissão, é o ator responsável pela coordenação desse processo. Cabe a ele reunir informações e repassá-las aos demais membros da comissão por meio de seu parecer. [...]. Regimentalmente o relator é um ator chave no processo de tramitação de uma matéria (Freitas, 2016, p. 81).

Almeida (2019) destaca que nos últimos anos houve um crescimento da produção legislativa oriunda do próprio Congresso Nacional e essa transformação foi acompanhada de um aumento no protagonismo das comissões. 
Porém, esse protagonismo não se deve apenas à produção legislativa dos próprios Congressistas, uma vez que se observando apenas os projetos de iniciativa presidencial também houve um incremento no papel exercido pelas comissões. Dessa maneira, o estudo das comissões torna-se relevante para uma melhor compreensão do processo legislativo devido ao papel desempenhado por elas nas alterações, discussões e negociações sobre os projetos e mesmo pelo seu poder de decidir terminativamente/conclusivamente e propor projetos próprios.

Outro foco de análise sobre as comissões é a forma de seleção dos membros para as mesmas. Como dito anteriormente, a indicação para as comissões no Brasil é feita pelos líderes partidários, cabendo saber quais os critérios usados nessas indicações. Santos (2002) aponta as diferenças existentes na indicação de membros para as comissões entre os períodos 1946-64 e pós-1988 ao estudar as comissões de Constituição e Justiça e a de Finanças e Tributação da Câmara dos Deputados destacando que o fator levado em consideração para a nomeação de membros pelos líderes partidários é a expertise, enquanto que a questão da lealdade partidária só é significativa no período 1946-64, ou seja no presidencialismo de coalizão facccionalizado. Resumidamente,

Em um modelo faccional os líderes combinam os critérios de lealdade partidária e a qualidade de especialistas em políticas públicas, estipulando um grau mínimo de lealdade para um parlamentar ser indicado para uma comissão muito importante, ao passo que no modelo racionalizado apenas a qualidade de especialista apareceu como determinante (Santos, 2002, p. 257)

Araújo (2017), ao estudar as comissões no Senado Federal aponta que, devido ao caráter hibrido - combinando elementos do modelo partidário, informacional e distributivo -, a seleção dos membros para as comissões levaria em consideração uma série de fatores, que variariam de acordo com a centralidade e atuação da comissão no dia a dia da casa legislativa. Dessa forma, as comissões de Constituição e Justiça e a de Assuntos Econômicos apresentariam maior peso da expertise e o poder do partido. Já para as outras comissões o caráter de autoindicação - típico do modelo distributivista - seria mais proeminente.

Além desses trabalhos sobre o recrutamento para as comissões em geral, há também trabalhos que tratam de comissões específicas: Ricci e Lemos (2004) analisaram a produção Legislativa na Comissão de Agricultura da Câmara dos Deputados; Lemos e Ranincheski (2008) estudaram as carreiras políticas na comissão de Constituição e Justiça do Senado; Pereira (2019) analisou o perfil dos parlamentares membros das comissões que tratam da temática de fiscalização e controle; Ferreira (2019) traça o perfil sociopolítico dos titulares da Comissão de Agricultura e Reforma Agrária e Souza e Silva (2019) analisa a composição da Comissão de Direitos Humanos e Legislação Participativa da câmara alta brasileira.

Por fim, há também trabalhos que analisam o desenvolvimento e institucionalização dos sistemas de comissões: Ribeiral (1998) aponta a institucionalização da Comissão de Constituição e Justiça; Lemos (2008) apresenta o desenvolvimento do sistema de comissões no Senado na década de 1990 e o caracteriza como centralizado nas comissões de Constituição e Justiça e Assuntos Econômicos; Vasquez e Freitas (2019) analisam as transformações do sistema de comissões a partir dos Projetos de Resolução, mostrando que as mudanças ocorridas visavam um sistema de comissões com maior grau de especialização, permitindo uma maior participação das comissões no processo legislativo da Câmara dos Deputados.

Dessa forma, é possível notar a crescente produção sobre as comissões do Legislativo brasileiro nas últimas décadas, passando de uma visão das comissões como pouco relevantes para o processo legislativo para uma abordagem 
que mostra a complexidade e o papel central exercido por elas na discussão e transformação dos projetos que tramitam nas casas legislativas.

\section{Capacidade decisória das comissões do Senado (1999-2018)}

Nessa seção serão analisadas as informações referentes a atuação legislativa das comissões, no que tange a capacidade de decisão das mesmas no interior do processo legislativo na câmara alta. Desta forma, se dará destaque ao uso do poder terminativo das comissões e das decisões finais tomadas por elas.

Para tanto foram analisadas as iniciativas que chegaram a uma decisão no Senado entre os anos de 1999 e 2018 . O período cobre cinco legislaturas e os governos FHC II, Lula I, Lula II, Dilma I, Dilma II e Temer. Foram analisados os Projetos de Lei, Projetos de Lei Complementares e Projetos de Emendas Constitucionais votados na câmara alta, totalizando 6.493 projetos decididos no período. Cabe aqui notar que foram excluídas as medidas provisórias por causa de seu trâmite especial: essas iniciativas, que só podem ser feitas pelo Executivo, iniciam seu trâmite em Comissões Mistas do Congresso Nacional, não sendo avaliadas pelas comissões permanentes da cada casa, indo direto para discussão em plenário.

Desta forma, os projetos decididos no Senado foram classificados por 1) sua origem (Executivo, Deputados, Senadores e Outros), 2) o local da decisão (comissões ou plenário, 3) o resultado no senado (aprovado ou rejeitado) e 4) as áreas dos projetos analisados. Com esses dados é possível apontar o papel desempenhado pelas comissões nas decisões tomadas na casa e as variações ocorridas no decorrer do período.

Um primeiro ponto a destacar é a capacidade de decisão final das comissões do Senado. Como se pode observar na Tabela 1, entre os anos de 1999 e 2018, a distribuição dos resultados entre plenário e comissões é bem equilibrada, ficando as comissões responsáveis por pouco menos da metade das decisões. Este ponto reforça a imagem das comissões como lócus importante do processo legislativo: além de ser responsável pela questão informacional, as comissões também são responsáveis por grande parte das decisões tomadas. Cabe notar que apenas as decisões finais tomadas nas comissões foram contadas, isto é, não se considerou os pareceres emitidos nas comissões que foram ao plenário, o que reforçaria ainda mais a imagem da importância do sistema de comissões no processo decisório do Senado.

Entretanto, essa utilização das comissões como espaço decisório não ocorre de maneira homogênea em todo o período estudado: nas duas legislaturas compreendidas entre os anos de 2007 e 2014, mais da metade das decisões foram tomadas nas comissões $(59,8 \%$ entre $2007-2010$ e $56,2 \%$ entre 2011-2014). Portanto, as legislaturas que compreendem o segundo mandado de Lula e o primeiro de Dilma aparecem com uma maior participação das comissões enquanto agentes decisórios, isto é, como local de tomada de decisão final no Senado.

Tabela 1 - Participação das comissões e do plenário nas decisões finais tomadas no Senado (porcentagens): 1999-2018

\begin{tabular}{lcccccc}
\hline & $\mathbf{1 9 9 9 - 2 0 0 2}$ & $\mathbf{2 0 0 3 - 2 0 0 6}$ & $\mathbf{2 0 0 7 - 2 0 1 0}$ & $\mathbf{2 0 1 1 - 2 0 1 4}$ & $\mathbf{2 0 1 5 - 2 0 1 8}$ & Total do período \\
\hline Plenário & 55,5 & 60,7 & 40,2 & 43,8 & 64,5 & 51,1 \\
Comissões & 45,5 & 39,3 & 59,8 & 56,2 & 35,5 & 48,9 \\
\hline
\end{tabular}

Fonte: Elaborado pelo autor. 
Os estudos legislativos no Brasil apontam corriqueiramente que o processo legislativo é centralizado nas lideranças partidárias, ficando as comissões e outros espaços descentralizados do Legislativo mitigados por essa centralização (Limongi e Figueiredo, 1998). Observando as duas primeiras legislaturas aqui apresentadas, pode-se notar que, de fato, a maior parte das decisões tomadas no Senado ocorreram no plenário. Todavia, o quadro das duas legislaturas seguintes altera essa perspectiva: a maioria dos projetos decididos no Senado o foram nas comissões. $\mathrm{O}$ que poderia ter ocasionado essa alteração no processo decisório da câmara alta? Segundo Almeida (2015, 2016), a partir de 2005 o processo legislativo brasileiro sofreu algumas mudanças: da parte do Executivo o uso de Medidas Provisórias e Pedido de Urgência diminuíram, aumentando a utilização do rito ordinário, e a utilização do poder conclusivo das comissões sobre os projetos do Executivo triplicaram em 2007-2014 (Almeida, 2015).

Somado a essa mudança de comportamento do Executivo, temos também a alteração no tipo de coalizão formada. Almeida (2016) aponta que a delegação de poderes para as lideranças diminui conforme aumenta a heterogeneidade das preferências dos seus membros. Para o autor (Almeida, 2019, p, 419),

Supondo que existe uma maioria partidária, a dispersão do poder de agenda entre as comissões, onde a minoria opositora supostamente tem mais oportunidade de exercer influência, implica resultados legislativos mais próximos da preferência mediana do plenário e maiores custos de transação (por exemplo, com debates e manobras de obstrução da minoria). Por outro lado, quando a maioria concentra poderes de agenda na sua liderança, os resultados legislativos tornam-se mais próximos da preferência mediana do partido e diminuem-se os custos de transação. Assim, membros da maioria cujas preferências são mais próximas da mediana do partido (vis-à-vis a mediana do plenário) têm incentivo para delegar poderes ao seu líder, e esse incentivo é crescente na distância entre as medianas do partido minoritário e do majoritário, em razão de o incentivo da minoria para impor maiores custos de transação ser crescente nessa distância.

Nesse sentido coalizões majoritárias mais homogêneas teriam maior incentivos para a delegação de poderes para os líderes, enquanto que as mais heterogêneas apresentariam uma maior dispersão na tomada de decisões, aumentando as decisões em organismos descentralizados como as comissões.

Ao observar que as coalizões dos governos Lula e Dilma apresentam maior heterogeneidade partidária se comparadas com seus antecessores - expressa tanto no número de partidos que as compõem, quanto pela distância ideológica entre eles -, é possível que a delegação da decisão para os líderes seja enfraquecida.

O aumento da heterogeneidade da coalizão, pode também ser utilizados para explicar o aumento da utilização das decisões por comissões no Senado Federal nessas duas legislaturas, que correspondem aos governos Lula e Dilma: esses governos apresentaram coalizões que contavam com oito e nove partidos, sendo que eles se distribuíam entre partidos de esquerda, centro e direita, ou seja, coalizões com grande número de parceiros e com alta heterogeneidade ideológica.

Cabe ainda destacar que a legislatura em que as comissões tiveram menor papel como decisoras foi a de 2015-2018. Entretanto, deve-se levar em conta que essa legislatura foi marcada por um processo de impeachment que afastou a presidenta eleita em 2014 e deu início ao governo Temer, isto é, essa legislatura contou com dois governos distintos.

Por esse motivo, cabe separar as decisões tomadas no Senado no governo Dilma e no Governo Temer. Para tanto, na Tabela 2, foi considerado governo Dilma o período que se estende da posse do segundo mandato até o dia 12 de maio de 2016, data em que o Senado aprova a instauração do processo e a então 
Tabela 2 - Decisões no Senado Federal por legislatura: governos Dilma e Temer

\begin{tabular}{lcc}
\hline & Dilma & Temer \\
\hline Plenário & 54,1 & 70,6 \\
Comissões & 45,9 & 29,4 \\
\hline
\end{tabular}

Fonte: Elaborado pelo autor.

presidenta é afastada. Para o governo Temer estão incluídos o período de presidente interino até o final do mandato.

Como se pode observar pela Tabela 2, a utilização da decisão final pelas comissões cai para 29,3\% durante o governo Temer, ficando então o plenário como principal lócus de decisão. Novamente, as características da coalizão de apoio ao governo podem estar relacionadas a essa situação: o governo Temer apresentou uma coalizão mais homogênea, baseada em partidos de centro e de direita do espectro político, o que, como dito acima pode ter reforçado a tendência a centralizar decisões nos líderes - uma vez que as distâncias entre as preferências entre eles e o mediano da base estariam reduzidas - o que, por conseguinte, enfraquece a descentralização de decisão para as comissões. Por outro lado, o segundo mandato de Dilma apresenta coalizão semelhante a anterior: alto número de partidos (entre nove e dez) que se espalham por todos os campos do espectro ideológico, além de serem altamente instáveis - sendo cinco coalizões distintas em um período de aproximadamente um ano e meio.

Um segundo ponto a ser tratado sobre as decisões no Senado Federal é o tipo de decisão tomada em cada um dos espaços decisórios, isto é, o local onde são aprovados e rejeitados os projetos de lei avaliados no Senado (Tabela 3). Para tanto, foram considerados aprovados todos os projetos que seguiram o trâmite legislativo bicameral, isto é, tanto os projetos que seguiram para a sanção presidencial quanto os projetos que foram enviados para a câmara dos deputados. Já os projetos "rejeitados" contam com todos os resultados negativos, com exceção do arquivamento por força do regimento, isto é, projetos efetivamente rejeitados, prejudicados e retirados são aqui agrupados como rejeitados.

Cabe destacar os projetos "arquivados por força do regimento". Pelo artigo 332 do Regimento Interno do Senado, são arquivados no final da legislatura todas as proposições, com algumas exceções, por exemplo, as originadas na Câmara, as de Senadores que permanecem em exercício, as com parecer favorável das comissões (BRASIL, 2019). Sendo que, mesmo essas exceções serão arquivadas após duas legislaturas. Como apontado por Rubiatti (2017a), a maior frequência de retenção de projetos em revisão no Senado se dá por esse dispositivo, ou seja, não há uma votação sobre a rejeição e sim uma "não-decisão" da casa sobre o projeto. Nesse sentido, as comissões também realizam esse tipo de ação: retém os projetos em seu interior, sem votar um relatório sobre os mesmos, impedindo assim que o mesmo chegue até o plenário. Dessa forma, esse tipo de arquivamento mostra o gatekeeping power das comissões. Todavia, projetos "arquivados por força do regimento" não entraram na análise

Tabela 3 - As aprovações e rejeições de projetos no Senado Federal: comissões e plenário (1999-2018)

\begin{tabular}{lcc}
\hline & Aprovações & Rejeições \\
\hline Comissões & 52,8 & 39,5 \\
Plenário & 47,2 & 60,5 \\
\hline
\end{tabular}

Fonte: Elaborado pelo autor. 
pois representam o poder negativo das comissões, saindo do foco da análise aqui apresentada.

No que tange as aprovações, pode-se observar na Tabela 3 que as comissões são responsáveis por mais da metade dos projetos que tiveram resultado positivo em seu trâmite no Senado Federal. Por outro lado, o plenário é o principal local de projetos rejeitados.

Outro ponto importante é saber como os diferentes locais decisórios atuam, ou seja, qual o grau de aprovações e rejeições do sistema de comissões e do plenário. Como se pode notar na Tabela 4, as comissões apresentam um maior grau de aprovações: $76,1 \%$ dos projetos por elas analisados foram aprovados. Cabe notar que, mesmo apresentando um maior grau de retenções, o plenário também mostra um forte grau de aprovação de projetos (65\%). Desta forma, pode-se dizer que nem o plenário nem as comissões se mostram como barreiras intransponíveis para os projetos analisados, pelo contrário, ambos apresentam uma alta taxa de aprovação (Tabela 5).

Por fim, cabe observar o local de aprovação e rejeição por legislatura. No que tange as aprovações, observa-se que as comissões têm importante papel, mas com variações de acordo com a Legislatura. Nas duas primeiras legislaturas analisadas o plenário foi o local predominante das aprovações no Senado. Porém, as comissões ficam com mais de $40 \%$. O quadro se inverte no segundo mandato de Lula e no primeiro de Dilma Rousseff. Nas legislaturas correspondentes a esses dois mandatos presidenciais, as comissões foram responsáveis por mais da metade das aprovações, ficando a primeira com $67,3 \%$ e a segunda com $60,5 \%$ das decisões. Todavia, na última legislatura analisada, a participação das comissões nas aprovações volta a cair para menos de $50 \%$, atingindo o menor patamar de toas as legislaturas: $37,3 \%$. Novamente, essa queda na participação das comissões nas decisões pode estar ligada a crise política que culminou no processo de impeachment e a mudança na coalizão de apoio ao governo.

No que tange as rejeições, observa-se um quadro distinto (Tabela 6). Apesar de, em linhas gerais, a participação das comissões nas rejeições apresentarem crescimento semelhante ao das aprovações, isto é, aumentam nas duas legislaturas compreendidas entre 2007 e 2014 e caem na legislatura seguinte, pode-se notar que em nenhuma legislatura as comissões foram responsáveis por mais da metade das rejeições.

Tabela 4 - Comissões e Plenário: Aprovações e rejeições (\%) (1999-2018)

\begin{tabular}{lcc}
\hline & Comissões & Plenário \\
\hline Aprovações & 76,1 & 65,0 \\
Rejeições & 23,9 & 35,0 \\
Total & 100 & 100 \\
\hline
\end{tabular}

Fonte: Elaborado pelo autor.

Tabela 5 - As aprovações no Senado Federal: comissões e plenário (1999-2018)

\begin{tabular}{lccccc}
\hline & $\mathbf{1 9 9 9 - 2 0 0 2}$ & $\mathbf{2 0 0 3 - 2 0 0 6}$ & $\mathbf{2 0 0 7 - 2 0 1 0}$ & $\mathbf{2 0 1 1 - 2 0 1 4}$ & $\mathbf{2 0 1 5 - 2 0 1 8}$ \\
\hline Plenário & 53,5 & 58,2 & 32,7 & 39,5 & 62,7 \\
Comissões & 46,5 & 41,8 & 67,3 & 60,5 & 37,3 \\
\hline
\end{tabular}

Fonte: Elaborado pelo autor. 
Tabela 6 - As rejeições no Senado Federal: comissões e plenário (1999-2018)

\begin{tabular}{lccccc}
\hline & $\mathbf{1 9 9 9 - 2 0 0 2}$ & $\mathbf{2 0 0 3 - 2 0 0 6}$ & $\mathbf{2 0 0 7 - 2 0 1 0}$ & $\mathbf{2 0 1 1 - 2 0 1 4}$ & $\mathbf{2 0 1 5 - 2 0 1 8}$ \\
\hline Plenário & 63,5 & 67,7 & 58,2 & 52,1 & 68,9 \\
Comissões & 36,5 & 32,3 & 41,8 & 47,9 & 31,1 \\
\hline
\end{tabular}

Fonte: Elaborado pelo autor.

Em suma, é possível perceber que as comissões do Senado Federal, no que tange ao uso do poder terminativo, apresentam uma maior propensão a aprovação. Todavia, isso não significa que as comissões simplesmente aprovam os projetos a ela enviados. Se retomarmos a ideia que as comissões são as responsáveis por estabelecer acordos e negociações entre os partidos e membros do Legislativo, pode-se intuir que essa taxa de sucesso dos projetos nas comissões estaria ligada ao sucesso dessa negociação realizada no interior das próprias comissões, onde a figura do Relator acabaria ganhando destaque, como foi afirmado por Freitas (2016). Todavia, para se confirmar esse ponto seria necessário observar que tipo de decisão foi tomada dentro das comissões, isto é, se as comissões aprovam substitutivos, os projetos com emendas ou o projeto original sem alterações.

\section{O poder positivo das comissões: as matérias aprovadas no Senado Federal}

Cabe agora apontar o que as comissões aprovam. Para tanto, serão analisados os projetos aprovados em decisão das comissões a partir dos seguintes elementos: 1) propositor e 2) área temática do projeto.

Sobre o primeiro ponto, cabe notar que as comissões no Senado aprovam de forma terminativa majoritariamente as proposições dos próprios Senadores. Este fato é esperado uma vez que as proposições dos Deputados, do Executivo e de outros atores com capacidade de iniciativa começarem seu trâmite pela Câmara dos Deputados, ou seja, esses projetos já passaram por uma filtragem anterior, ao contrário dos projetos formulados por Senadores, desta forma, o volume de iniciativas dos próprios senadores acaba sendo maior. Além disso, cabe apontar que há uma forte restrição ao uso do poder terminativo pelas comissões do Senado no que tange projetos vindos da Câmara dos Deputados: o artigo 91 do RISF (BRASIL, 2019) determina que o presidente do Senado, após ouvir as lideranças, poderá conceder o uso do poder terminativo para matérias vindas da Câmara dos Deputados apenas para projetos que passaram por decisão terminativa de comissão naquela casa. Em outras palavras, apenas uma parte dos projetos oriundos da Câmara dos Deputados - os decididos pelo poder conclusivo das comissões dessa casa - pode ser objeto de decisão terminativa no Senado (Tabela 7).

Tabela 7 - As aprovações nas comissões no Senado Federal: órgãos propositores (1999-2018)

\begin{tabular}{lc}
\hline Propositor & Porcentagem \\
\hline Senado & 85,2 \\
Deputados & 11,9 \\
Executivo & 1,6 \\
Outros & 1,3 \\
\hline
\end{tabular}

Fonte: Elaborado pelo autor. 
Outro ponto a se destacar sobre os órgãos propositores é que apenas a partir do ano de 2008 as proposições de Deputados, Executivo e Tribunais Superiores apresentam decisão final nas comissões do Senado, isto é, nas duas primeiras legislaturas analisadas o plenário foi o único local de decisão para as propostas originadas externamente ao Senado. Sobre os projetos iniciados por Deputados, destaca-se que $41 \%$ dos projetos aprovados entre 2009 e 2010 o foram nas comissões. Na legislatura seguinte (2011-2014) 66,2\% dos projetos dos deputados foram decididos dentro das comissões. Entretanto, na última legislatura apenas $5 \%$ dos projetos dos deputados tiveram esse desfecho.

No que tange aos projetos do Executivo, as aprovações por comissões se iniciaram em 2008 e a última registrada foi em 2013. Ao contrário do que ocorre com os projetos dos deputados, em nenhum momento as comissões foram responsáveis pela maioria das aprovações. Excetuando-se as Medidas Provisórias (e projetos de lei de conversão), as comissões foram responsáveis pela aprovação de 31,3\% dos projetos do Executivo entre 2008-2010 e 11,4\% entre 2011-2013, sendo que no restante do período analisado não houve ocorrência de decisão de projetos do Executivo em comissões do Senado Federal.

Desta maneira, pode-se notar que em apenas alguns momentos as decisões referentes aos projetos do Executivo foram feitas pelas comissões. Apesar da considerável participação das comissões nas decisões dos projetos do Executivo entre 2008-2010, ela ainda não atinge metade das decisões. Somado a isso, já na legislatura seguinte, essa participação cai bruscamente e retorna a zero, o mesmo patamar que se encontrava antes de 2008.

Já para os projetos de deputados aprovados no Senado, se observa uma maior participação das comissões na decisão. Todavia, a última legislatura mostra uma queda considerável nessa participação, mesmo que não tenha retornado à ausência de decisões pelas comissões, como era o caso antes de 2009.

Além da origem, cabe também observar a área temática dos projetos decididos nas comissões, com o objetivo de observar que tipo de matéria as comissões decidem. Para tanto será utilizada a classificação dos projetos nas áreas i) social, ii) econômica, iii) jurídica, iv) administrativa e v) honorífica. A Tabela 8 apresenta essa distribuição por legislatura e no total de leis aprovadas nas comissões do Senado no período analisado.

Como se pode notar, a maior parte das decisões é classificada como social: 42,5\% dos projetos aprovados em comissão no período de 1999 até 2018 são assim classificados. Ao observar essa distribuição por período legislativo, nota-se alguma variação, de $38 \%$ até $46,1 \%$. Em todo caso, os projetos de cunho social estão sempre na primeira posição entre os projetos decididos em comissões no Senado. A segunda maior frequência é de projetos que tratam de questões jurídicas (códigos e assuntos correlatos), que representam 19,1\% dos

Tabela 8 - As aprovações nas Comissões no Senado Federal: áreas temáticas (1999-2018)

\begin{tabular}{lcccccc}
\hline & $\mathbf{1 9 9 9 - 2 0 0 2}$ & $\mathbf{2 0 0 3 - 2 0 0 6}$ & $\mathbf{2 0 0 7 - 2 0 1 0}$ & $\mathbf{2 0 1 1 - 2 0 1 4}$ & $\mathbf{2 0 1 5 - 2 0 1 8}$ & Total do período \\
\hline Social & 38,0 & 41,3 & 40,7 & 46,1 & 44,7 & 42,5 \\
Econômica & 15,6 & 12,9 & 16,0 & 12,1 & 17,0 & 14,7 \\
Jurídica & 21,3 & 23,8 & 19,0 & 13,9 & 23,3 & 19,1 \\
Administrativa & 4,6 & 4,5 & 10,5 & 3,6 & 6,9 & 6,8 \\
Honorífica & 20,5 & 17,5 & 13,8 & 24,3 & 8,1 & 16,9 \\
\hline
\end{tabular}

Fonte: Elaborado pelo autor. 
projetos aprovados pelas comissões do Senado - apenas na legislatura que compreende os anos de 2011-2014 os projetos dessa natureza deixam de ocupar a segunda maior frequência.

Os projetos honoríficos representam 16,9\% dos projetos decididos em comissões no período. Neste caso, há uma grande variação na frequência de projetos aprovados por período legislativo: 8,1\% em 2015-2018 e 24,3\% em 2011-2014. No caso dos projetos de natureza econômica, nota-se uma baixa variação nas diferentes legislaturas: esses projetos atingem aproximadamente entre $12 \%$ e $16 \%$ das decisões. Por fim, os projetos com menor frequência de decisões em comissões são os projetos de natureza administrativa, que representam $6,8 \%$ do total dessas decisões. Apesar de sua pequena presença, esses projetos variam entre aproximadamente 3\% e 10\% dos projetos aprovados por decisão terminativa. Um ponto que pode explicar essa baixa frequência de projetos econômicos e administrativos é o papel central desempenhado pelo Executivo nessas áreas e, como observado anteriormente, poucos projetos do Executivo passam por decisão terminativa nas comissões do Senado.

Cabe ainda destacar que, pelos dados antes expostos, não é possível afirmar que as comissões tomem decisões em áreas de baixa relevância. Se considerarmos os temas sociais e econômicos, podemos ver que eles sempre ocupam mais da metade das decisões das comissões. Somado a isso, as decisões de projetos honoríficos ocupam apenas a terceira maior frequência em todo o período, sendo que se nota uma queda em sua frequência por legislatura, excetuando-se a de 2011-2014.

\section{Considerações Finais}

As comissões no legislativo brasileiro exercem funções tanto deliberativas quanto informacionais. Nesse artigo buscou-se apontar qual o papel decisório das comissões do Senado Federal, focando apenas nas decisões finais tomadas por essas comissões. Esse poder terminativo das comissões do Senado garante a elas um papel relevante no processo legislativo, mas a participação das comissões nesse processo não se limita a ele: as comissões também são espaços de negociação, discussão e formulação de pareceres que posteriormente serão apreciados pelo plenário, ou seja, mesmo as decisões de plenário podem ocorrer após a formulação de acordos ocorridos no interior das comissões.

Ao se tratar do local de decisão no Senado Federal, observa-se que no período que se estende de 1999 a 2018 há certo equilíbrio entre plenário e comissões: apesar do plenário decidir pouco mais da metade dos projetos de lei, as comissões atingem uma participação de $48,9 \%$. Todavia, essa participação das comissões varia de acordo com a legislatura analisada. As duas primeiras legislaturas (1999-2002 e 2003-2006) mostram uma maior preponderância da atuação do plenário, mas esse quadro muda nas duas legislaturas seguintes, onde as comissões passam a ser responsáveis por mais da metade das decisões tomadas na câmara alta.

Esse crescimento da atuação das comissões no Senado pode estar relacionado com o tipo de coalizão de governo formado no período: nessas duas legislaturas, os governos formados apresentam alto número de partidos e grande heterogeneidade ideológica, o que dificulta a delegação de poderes e centralização nos líderes, uma vez que as preferências dos parlamentares que compõem a maioria se afastam da posição dos líderes. Nesse quadro, os parlamentares teriam maior propensão para descentralizar o processo decisório, reforçando o papel das comissões.

Essa possível relação entre a heterogeneidade da coalizão e a utilização da decisão nas comissões parece ser reforçada com o fato de que na última 
legislatura estudada (2015-2018) volta-se a ter uma prevalência do plenário nas decisões. Cabe aqui destacar que essa é uma legislatura atípica: nela ocorre um processo de impeachment e uma mudança de governo onde a coalizão passa a ser formada por partidos de centro e direita, ou seja, com menor heterogeneidade. Ao mesmo tempo, esse período é marcado pela menor utilização das comissões como espaço de decisão final no Senado brasileiro, chegando a $29,4 \%$ das decisões.

Outro ponto que foi possível notar foi o poder positivo das comissões do Senado. Nesse sentido, as comissões aprovam a maior parte dos projetos por ela decididos (excetuando-se os projetos "arquivados por força do regimento"), além de serem responsáveis por mais da metade das aprovações ocorridas na câmara alta no período de 1999 a 2018. Todavia, isso não significa que as comissões não sirvam de filtro de proposições, uma vez que parte das propostas são por ela rejeitadas e, somado a isso, caberia apontar se a aprovação das comissões não envolve emendamentos e apresentação de substitutivos, reforçando a imagem das comissões como local de discussão, negociação e alteração dos projetos. Entretanto, esse levantamento sobre emendamentos/substitutivos foge do escopo desse artigo, ficando como uma agenda aberta para futuros trabalhos.

Sobre a origem dos projetos apreciados terminativamente pelas comissões da câmara alta, observa-se uma predominância de projetos dos próprios senadores. Isso é esperado uma vez que a maior parte dos projetos analisados na casa é de origem do próprio Senado. Isso se dá pois os projetos dos Deputados Federais, Executivo, Tribunais Superiores e Iniciativa Popular tem seu início na Câmara dos Deputados, que já serve como um primeiro filtro, ficando o Senado como câmara revisora. Além disso, apenas uma parte restrita dos projetos em revisão no Senado podem ser alvo de decisão terminativa - apenas os que foram decididos conclusivamente nas comissões da câmara de origem (Câmara dos Deputados).

Ainda no tocante a esse ponto, cabe notar que apenas em 2008 os projetos originados fora do Senado passam a ter decisão final nas comissões, ou seja, no mesmo momento em que as coalizões de governo formadas apresentam maior tamanho e heterogeneidade. Somado a isso, na última legislatura, os projetos do Executivo não foram decididos terminativamente nas comissões e os de autoria dos deputados também apresentaram grande queda na participação de decisões finais nas comissões.

Por fim, um último ponto a destacar é a área temática desses projetos. Como mostrado, a temática social ocupa a maior parte das decisões positivas das comissões, seguida da área jurídica. Os projetos de lei honorificas representam apenas $16,9 \%$ e sua distribuição no decorrer das diferentes legislaturas apresenta grande variação. De todo modo, isso permite apontar que não são esses os projetos que formam a maior parte das decisões das comissões, isto é, as comissões decidem projetos substantivos, não se limitando apenas a projetos de lei de caráter simbólico.

Em suma, o presente artigo buscou mapear a atuação das comissões no Senado Federal, destacando seu papel como agente decisório no processo legislativo, contribuindo para a compreensão do processo legislativo no interior da câmara alta. Observou-se que as comissões apresentam forte capacidade de decisão e que essa capacidade pode ser ainda mais fortalecida caso a coalizão de governo se mostre heterogênea. Cabe ainda destacar que o estudo sobre a atuação das comissões no Senado Federal ainda precisa de mais esforços de pesquisa, por exemplo, a análise sobre as emendas e substitutivos aprovados pelas comissões, a taxa de sucesso dos pareceres das comissões nas decisões do plenário, o papel informacional que as comissões possuem, a atuação da base 
governista e o espaço de atuação das minorias parlamentares no interior das comissões ainda são temáticas a serem exploradas pelos estudos legislativos brasileiros.

Bruno de Castro Rubiatti (bcrubiatti@ hotmail.com) é Doutor em Ciência Política pela Unicamp e professor do Programa de Pós-Graduação em Ciência Política UFPA.

\section{Referências}

Almeida, A. (2015) Processo legislativo: mudanças recentes e desafios. [online] Boletim de Análise Político-Institucional, s/v(7), Rio de Janeiro: Ipea. Disponível em <http://repositorio.ipea.gov.br/handle/11058/6788>. Acesso em 29. Abr. 2021

Almeida, A. (2016) A política da mudança institucional: processo legislativo no Brasil pós-1988. In: 40 Encontro Anual da Anpocs, Caxambu.

Almeida, A. (2019) Do plenário às comissões: mudança institucional na Câmara dos Deputados. In: G. Perlin. \& M.L. Santos,(orgs) Presidencialismo de coalizão em movimento. Brasília: Edições Câmara.

Amaral, A. R. V. P. (2011). O Parlamento Brasileiro: Processo, Produção e Organização Legislativa - O Papel das Comissões em Perspectiva Comparada. In: Nicolau, J. \& BRAGA, R. J. (orgs.). Para além das urnas: reflexões sobre a câmara dos deputados. Brasília: Centro de documentação e Informação-Edições Câmara, p. 149-177.

Araújo, P.M (2008) A Câmara Alta no presidencialismo brasileiro: o desempenho legislativo do Senado entre 1989 e 2000. In: L. B. Lemos (orgs) O Senado Federal brasileiro no pós-constituinte. Brasília: Senado Federal, Unilegis, p. $203-236$.

Araújo, P.M (2017) Comissões no Senado Federal: perfil social e trajetória política na triagem dos senadores no sistema comissional. Cadernos da Escola do Legislativo, 19(32), pp. 97-138.

Backes, A.L (2008) Fortalecimento parlamentar de minorias regionais e suas razões. In: L.B. Lemos, (orgs) O Senado Federal brasileiro no pós-constituinte. Brasília: Senado Federal; Unilegis, p. 63-84.

Bohn, S. (2008) Mulheres e qualidade das candidaturas nas eleições para o Senado: Brasil e Estados Unidos em contraste. In: L.B. Lemos (orgs) O Senado Federal brasileiro no pós-constituinte. Brasília: Senado Federal; Unilegis, p. 151-199.

Busanello, E. \& Rehbein, M. (2017) As deputadas federais na presidência e vicepresidência das comissões permanentes da câmara dos deputados: quem são elas e como chegaram lá? E-legis, 10(23), p. 106-32. DOI: 10.51206/e-legis.v10i23.307

Cox, G.W. \& MCubbins, M.D. (1993) Legislative leviathan: party government in the house. Berkeley: University of California Press.

Ferreira, W.R.S. (2019) Perfil sociopolítico dos membros titulares da Comissão de Agricultura e Reforma Agrária do Senado Federal. Caos - Revista Eletrônica de Ciências Sociais, 2s/v(23), pp. 113-38. DOI: 10.46906/caos.n23.48238.p113-138

Freitas, A. (2016) O presidencialismo da coalizão. Rio de Janeiro: Fundação Konrad Adenauer.

Izumi, M.Y. (2016) Governo e Oposição no Senado Brasileiro (1989-2010). Dados, 59(1), pp. 91-138. DOI: $10.1590 / 00115258201672$

Krehbiel, K. (1991) Information and legislative organization. Ann Arbor: The University of Michigan Press.

Lemos, L. B. (2008) O sistema de comissões no Senado brasileiro: hierarquia e concentração de poderes nos anos 1990. In: L. B. Lemos (orgs) O Senado Federal brasileiro no pós-constituinte. Brasília: Senado Federal; Unilegis.

Lemos, L. B. \& Llanos, M. (2008) O Senado e as aprovações de autoridades: um estudo comparativo entre Argentina e Brasil. In: L. B. Lemos (orgs) O Senado Federal brasileiro no pós-constituinte. Brasília: Senado Federal; Unilegis.

Lemos, L.B. \&Ranincheski, S. (2008) Carreiras políticas no Senado brasileiro: um estudo das composições do Plenário e da Comissão de Justiça e Cidadania na década de 1990. In: L. B. Lemos (orgs) O Senado Federal brasileiro no pós-constituinte. Brasília: Senado Federal; Unilegis.

Lijphart, A. (2008) Modelos de democracia. Rio de Janeiro: Civilização Brasileira.

Limongi, F. \& Figueiredo, A. (1998) Bases Institucionais do Presidencialismo de coalizão. Lua Nova, s/v(44), pp. 81-106. DOI: 10.1590/S0102-64451998000200005

Llanos, M. \& Nolte, D. (2003) Bicameralism in the Americas: around the extremes of symmetry and incongruence. The Journal of Legislative Studies, 9(3), pp. 54-86. DOI: 10.1080/1357233042000246864

Llanos, M. \& Sánchez, F. (2008) Conselho de anciãos? O Senado e seus membros no Cone Sul. In: L. B. Lemos (orgs) $O$ Senado Federal brasileiro no pós-constituinte. Brasília: Senado Federal; Unilegis.

Mayhew, D.R. (2004) Congress: the electoral connection. New Haven: Yale University Press.

Melo, N.M.L. \& Batista, M. (2012). Diferentes, mas iguais? Padrões de disciplina partidária na Câmara e no Senado. Revista Política Hoje, 21(1), pp. 150-85.

Muller, G. (2005) Comissões e Partidos Políticos na Câmara dos Deputados: Um Estudo sobre os Padrões Partidários de Recrutamento para as Comissões Permanentes. Dados, 48(1), pp. 371-94. DOI: 10.1590/S0011-52582005000200005.

Nascimento, E. O. (2010) Os Modelos da Organização Legislativa: Distributivo, Informacional e Partidário. Revista Política Hoje, 19(2), pp. 365-97.

Neiva, P. (2008) Os poderes dos Senados de países presidencialistas e o caso brasileiro. In: L. B. Lemos (orgs) O Senado Federal brasileiro no pós-constituinte. Brasília: Senado Federal; Unilegis.

Neiva, P. (2010) Senado brasileiro: um conselho de anciãos? Revista de Informação Legislativa, 47,(187), pp. $269-279$. 
Neiva, P. (2011a) Coesão e disciplina partidária no Senado Federal. Dados, 54(2), pp. 289-318.DOI: $10.1590 /$ S0011-52582011000200003

Neiva, P. (2011b) Disciplina partidária e apoio ao governo no bicameralismo brasileiro. Revista de Sociologia e Política, 19(39), pp. 183-96. DOI: 10.1590/S0104-44782011000200013

Neiva, P. \& Izumi, M. (2012) Os doutores da Federação: formação acadêmica dos senadores brasileiros e variáveis associadas. Revista de Sociologia e Política, 20(41), pp. 171-192. DOI: 10.1590/S0104-44782012000100011

Neiva, P. \& Soares, M. (2013) Senado brasileiro: Casa Federativa ou Partidária? Revista Brasileira de Ciências Sociais, 28(81), pp. 97-115. DOI: 10.1590/S0102-69092013000100007

Pereira, C. \& Mueller, B. (2000) Uma teoria da preponderância do poder Executivo. O sistema de comissões no legislativo brasileiro. Revista Brasileira de Ciências Sociais, 15(43), pp. 45-67. DOI: 10.1590/S0102-69092000000200004

Pereira, F.S. (2019) Comissões Permanentes e perfil parlamentar: análise sociopolítica das comissões temáticas de fiscalização e controle do Senado brasileiro (1993 - 2018). Caos - Revista Eletrônica de Ciências Sociais, s/v(23), pp. 56-78. DOI: 10.46906/caos.n23.48243.p56-78

Perlin, G.D.B. (2019) Sub-representação feminina no sistema de comissões parlamentares: um indicador da exclusão das mulheres do jogo político. In: G. Perlin, \& M.L. Santos. Presidencialismo de coalizão em movimento. Brasília: Edições Câmara.

Ribeiral, T. B. (1998) Comissão de Constituição e Justiça: uma ilha de institucionalização no Congresso Nacional. Revista do Legislativo, s/v(24), pp. 66-82.

Ricci, P. (2008) A produção legislativa de iniciativa parlamentar no Congresso: diferenças e similaridades entre a Câmara dos Deputados e o Senado Federal. In: L. B. Lemos (orgs) O Senado Federal brasileiro no pós-constituinte. Brasília: Senado Federal; Unilegis.

Ricci, P. \& Lemos, L. B. (2004) Produção legislativa e preferências eleitorais na Comissão de Agricultura e Política Rural da Câmara dos Deputados. Revista Brasileira de Ciências Sociais, 19(55), pp. 107-29. DOI: 10.1590/S0102-69092004000200007

Rocha, M. M. \& Barbosa, C. F. (2008) Regras Incentivos e Comportamento: as comissões parlamentares nos países do cone sul. Revista de Sociologia e Política, 16-complementar(s/n), pp. 93-104. DOI: 10.1590/S0104-44782008000300007

Rubiatti, B. C. (2015) Incongruência e composição partidária no bicameralismo brasileiro. In: V. R. Carvalho \& M. Menezes. Política e Instituições no Brasil. Teresina: Ed. UFPI.

Rubiatti, B. C. (2017a) Sistema de resolução de conflitos e o papel do Senado como câmara revisora no Bicameralismo Brasileiro. Revista Brasileira de Ciência Política, s/v(23), pp. 35-74. DOI: 10.1590/0103-335220172302

Rubiatti, B. C. (2017b) Organização interna das Casas Legislativas da Argentina, Brasil e México: estratégias individualistas ou reforço da representação partidária? In: M. Menezes., B. Johas \&, O. Perez (orgs) Instituições políticas e sociedade civil. Teresina: EDUFPI, p. 201-237.

Rubiatti, B. C. (2018) O Senado frente as propostas da Câmara dos Deputados no bicameralismo brasileiro. Revista Debates, 12(2), pp. 169-199. DOI: 10.22456/1982-5269.80992

Rubiatti, B. C. (2019) Os Estudos Legislativos no Brasil: Agendas de Pesquisa. Caos - Revista Eletrônica de Ciências Sociais, 2(23), pp. 12-35. DOI: 10.46906/caos.n23.49418.p12-35

Santos, F. (2002) Partidos e Comissões no Presidencialismo de Coalizão. Dados, 45(2), pp. 237,64. DOI: $10.1590 /$ S0011-52582002000200003

Santos, F. \& Almeida, A. (2011) Fundamentos Informacionais do Presidencialismo de Coalizão. Curitiba: Appris.

Santos, F. \& Canello. J. (2016) Comissões Permanentes, Estrutura de Assessoramento e o Problema Informacional na Câmara dos Deputados do Brasil. Dados. 59(4), pp. 10.1590/001152582016109.

Souza e Silva, J. N. A. (2019) A Comissão De Direitos Humanos e Legislação Participativa (CDH) no Senado Brasileiro: Um Estudo Sobre Sua Composição (2005-2018). Caos - Revista Eletrônica de Ciências Sociais, 2(23), pp. 79-112. DOI: 10.46906/caos.n23.48175.p79-112

Vasquez, V. \& Freitas, G. (2019) Mudanças Institucionais e suas consequências: uma análise do sistema de comissões brasileiro. Caos - Revista Eletrônica de Ciências Sociais, 2(23), pp. 36-55. DOI: 10.46906/caos.n23.48236.p36-55

\section{Outras Fontes}

BRASIL (2019). Senado Federal. Regimento Interno do senado Federal (RISF). Disponível em: https://www25.senado.leg.br/web/atividade/regimento-interno. Acesso em: 10 de junho de 2019. 


\section{Beyond plenary: The decision-making role of the committees in Brazilian Federal Senate}

KEYWORDS: Legislative; Senate; Legislative Committees; Decision-making Process; Legislative Studies.

ABSTRACT Introduction: The Legislative studies in Brazil features a strong tradition of research on the Chamber of Deputies, leaving the Senate in the background. Even though a growing number of researchs on the Brazilian upper house has emerged in recent years, there is still a range of subjects not approached about the legislative process in this house. This article analyzes the decision-making role of the committees in the Brazilian Federal Senate. Materials and Methods: The objective is consider the results of the bills that have been processed in the Senate between 1999 and 2018, in other words, the projects that had a result in the Senate, totalizing 6493 projects among Ordinary Bills, Complementar Bill and Constitutional Amendment voted in brazilian High Chamber. The projects will be analyzed according to their outcome, proposer, place of decision (plenary or committees) and thematic area. From these period it is possible to realize not only the decision-making role of the commissions system, but also the transformations that occurred in the Senate during this time. Results: The committees are responsible for almost half of the decisions taken in the Federal Senate and that the decisions taken by them are not limited to symbolic policies. In addition, there is an increase of final decisions by committees in the legislatures between 2007 and 2014, which are marked by broad and heterogeneous coalitions of government, reinforcing the argument that coalitions of this type hinder the delegation and concentration of powers leaders. It is also observed that the decisions made within the commissions focus on projects originating in the Senate, and the projects proposed by the Executive have only been examined in terminative way at legislatures above. Discussion: Committees play an important role in decision-making: in addition to being informational spaces and creating agreements and changing projects, they also have an important role as decision-makers in this legislative house. However, the use of committees' decision-making prerogatives seems to be related to the capacity to centralize the decision-making process in party leaderships. This means that in contexts where the majority coalition is more heterogeneous and centralization becomes more difficult, the use of commissions, as decentralized decision space, increases.

This is an Open Access article distributed under the terms of the Creative Commons Attribution Non-Commercial License which permits unrestricted non-commercial use, distribution, and reproduction in any medium provided the original work is properly cited.

A produção desse manuscrito foi viabilizada através do patrocínio fornecido pelo Centro Universitário Internacional Uninter à Revista de Sociologia e Política. 